\title{
Self Assessment Pengelolaan Masalah Pada SIADIN Universitas Dian Nuswantoro berbasis COBIT 5
}

\author{
Self Assessment on Problem Manage in SIADIN Universitas Dian Nuswantoro \\ based on COBIT 5
}

\author{
Mella Cynthia Oktaviani ${ }^{1}$, Fajrian Nur Adnan ${ }^{2}$ \\ ${ }^{1,2}$ Fakultas Ilmu Komputer, Universitas Dian Nuswantoro Semarang \\ e-mail: ${ }^{1} 112201405073 @$ mhs.dinus.ac.id, ${ }^{2}$ fajrian@dsn.dinus.ac.id
}

\begin{abstract}
Abstrak
Universitas Dian Nuswantoro merupakan salah satu perguruan tinggi swasta di kota Semarang yang memberikan jasa pendidikan formal untuk gelar Diploma III (D3), Sarjana (S1), dan Magister (S2). Universitas Dian Nuswantoro sudah menggunakan sistem informasi guna menunjang proses bisnisnya. SiAdin merupakan sistem informasi akademik yang saling terintegrasi dengan berbagai sistem informasi lainnya. Dalam pelayanannya, SiAdin terdapat beberapa masalah yang sering berulang seperti masalah data nilai transkrip yang berbeda, materi perkuliahan yang eror ketika di upload, dan server yang sering down saat ujian online dan kegiatan penginputan KRS. Dari permasalahan diatas maka akan dilakukan Self Assessment berdasarkan domain Delivery, Service, And Support (DSS) yang berfokus pada pengelolaan masalah yaitu DSSO3 (Manage Problems) yang mengacu pada COBIT 5 dengan mengumpulkan data melalui wawancara, kuesioner dan survey lapangan / visitasi. Hasil dari penelitian ini adalah nilai capability level, nilai gap, dan rekomendasi/usulan strategi perbaikan, dokumen dan SOP yang dibutuhkan organisasi. Dari hasil pengumpulan data didapatkan nilai capability level saat ini berada pada level 1 sebesar 64,12\% dengan status L (Largely Achieved, sehingga perlu banyak perbaikan pada level 1-5 untuk mencapai level 5 seperti yang ditargetkan
\end{abstract}

Kata kunci-COBIT 5, Self Assessment, DSSO3, Pengelolaan Masalah, SiAdin

\begin{abstract}
Dian Nuswantoro University is one of the privat Universities in Semarang that provide formal education for Diploma III (D3), Bachelor (S1), and Master (S2) degrees. University Dian Nuswantoro used an information system named SiAdin. SiAdin is an academic information system that integrated with other information system to support business process. In this service, SiAdin has several problems such as different transcript data, document material error when upload, and server down during online exams, and KRS input activities. Based on the problems will be Self Assessment by domain Delivery, Service, And Support (DSS) which focuses on Manage Problems (DSSO3) refers to COBIT 5 by collecting data from interviews, questionnaires and visitations. The results of this study are the value of capability level, gap value, and recommendations improvement strategies, documents and SOP documents required by organization. From the data collection, the capability level as is at level 1 of 64,12\% with $\mathrm{L}$ (Largely Achieved) status. Therefore, a lot of improvement at 1-5 levels to reach level 5 as target level is needed
\end{abstract}

Keywords - COBIT 5, Self Assessment, DSSO3, Manage Problems, SiAdin 


\section{PENDAHULUAN}

Penggunaan dan pemanfaatan Teknologi Informasi (TI) saat ini sudah merupakan bagian yang sangat penting pada setiap sektor. Sektor pemerintahan maupun non pemerintahan menggunakan dan memanfaatkan teknologi informasi tersebut untuk meningkatkan proses bisnis perusahaan yang ada. Teknologi informasi tersebut memiliki peran dalam mendukung tujuan bisnis perusahaan/instansi dengan cara menyediakan informasi dan komunikasi yang akurat, cepat dan relevan, meningkatkan efektivitas dan efisiensi proses bisnis, mendukung pengambilan keputusan dan mendukung perkembangan inovasi. Pemanfaatan teknologi informasi pada perusahaan / instansi terus mengalami pertumbuhan, adanya pertumbuhan pada teknologi informasi salah satunya adalah dengan hadirnya IT Governace (Tata Kelola Teknologi Informasi). IT Governance merupakan usaha mensinergikan peran IT dan Governance untuk mencapai sasaran dan tujuan perusahaan / instansi. Dalam penerapan IT Governance untuk memberikan manfaat, rencana strategis teknologi informasi harus selalu berjalan sesuai dengan rencana dan tujuan perusahaan/instansi, termasuk instansi di lembaga pendidikan. Pentingnya IT Governance pada lembaga pendidikan salah satunya adalah untuk memastikan bahwa teknologi informasi (TI) yang ada dapat menopang, memperluas strategi dan tujuan dari lembaga pendidikan terkait, seperti Universitas.

Universitas adalah salah satu contoh instansi negara yang menyediakan pelayanan pendidikan formal tingkat perguruan tinggi sehingga memerlukan teknologi informasi yang baik. Untuk sebuah Universitas, teknologi informasi berupa sistem informasi telah menjadi aspek penting dalam mendukung pendidikan tinggi seperti dalam proses pendidikan, penelitian, administrasi, dan layanan. Seiring meningkatnya peran sistem informasi dalam proses layanan di Universitas, pelaksanaan, pengoprasian dan pengelolaan sumber daya sistem informasi yang ada harus diarahkan sejalan dengan arah dan strategi Universitas. Sebuah Universitas biasanya memiliki lebih dari satu sistem informasi, sistem informasi yang ada antara satu dengan lainnya saling terintegrasi guna menyediakan layanan informasi yang diperlukan Universitas. Banyaknya sistem informasi yang saling terintegrasi dan banyaknya aktivitas tentunya menghasilkan data yang sama banyaknya. Data yang banyak tersebut memungkinkan munculnya peluang adanya masalah. Masalah ini tentunya dapat mengganggu kinerja dari Universitas dan juga mengganggu jalannya strategi teknologi informasi dan strategi bisnis yang ada. Sistem informasi Universitas yang baik harusnya dapat mendukung kinerja Universitas sesuai dengan strategi bisnis Universitas. Untuk mengukur seberapa optimal strategi teknologi informasi dan strategi bisnis yang ada sekarang, diperlukan Self Assessment.

Self assessment berdasarkan framework COBIT adalah satu dari banyak cara penilaian yang dapat digunakan untuk mengukur pada tingkat berapa tata kelola teknologi informasi (IT Governance) yang ada saat ini. Self assessment ini penting karena selain bisa mengukur berapa tingkat kapabilitas tata kelola teknologi informasi (IT Governance) sekarang, juga dapat memberikan rekomendasi bagaimana meningkatkan tingkat kapabilitas tata kelola teknologi informasi (IT Governace) yang ada berdasarkan dari segi aspek - aspeknya yang telah dikelompokkan. Beberapa penelitian telah dilakukan terkait Self Assessment ini seperti pada penelitian [1] yang melakukan Self Assessment pada Universitas Mercu Buana untuk mengukur dan menilai sejauh mana IT Governance Universitas dengan menggunakan framework COBIT 4.1. penelitian lainnya di bidang self assessment [2] melakukan Self Assessment pada Universitas Pendidikan Indonesia untuk menilai dan mengukur IT Governace Universitas yang ada dengan menggunakan kombinasi antara framework COBIT 4.1 dan Balanced Scorecard (BSC).

Pada penelitian ini akan melakukan Self Assessment dengan menggunakan framework COBIT 5 dengan sub domain DSS03 (Manage Problems) yang berfokus pada proses pengelolaan masalah pada Sistem Informasi Akademik Universitas Dian Nuswantoro (SiAdin) untuk mengetahui sejauh mana tingkat tata kelola pengelolaan masalah pada SiAdin yang ada saat ini. Adapun data yang digunakan dalam penelitian ini diperoleh dari wawancara, kuesioner, dan survey lapangan / visitasi yang mengacu pada temuan / bukti yang ada dilapangan.

Journal of Information System Vol.4, No. 1, Mei 2019, hlm. 19-30 


\section{METODE PENELITIAN}

Adapun tahapan analisis yang dilakukan pada penelitian ini terdapat pada Gambar 1 berikut ini :

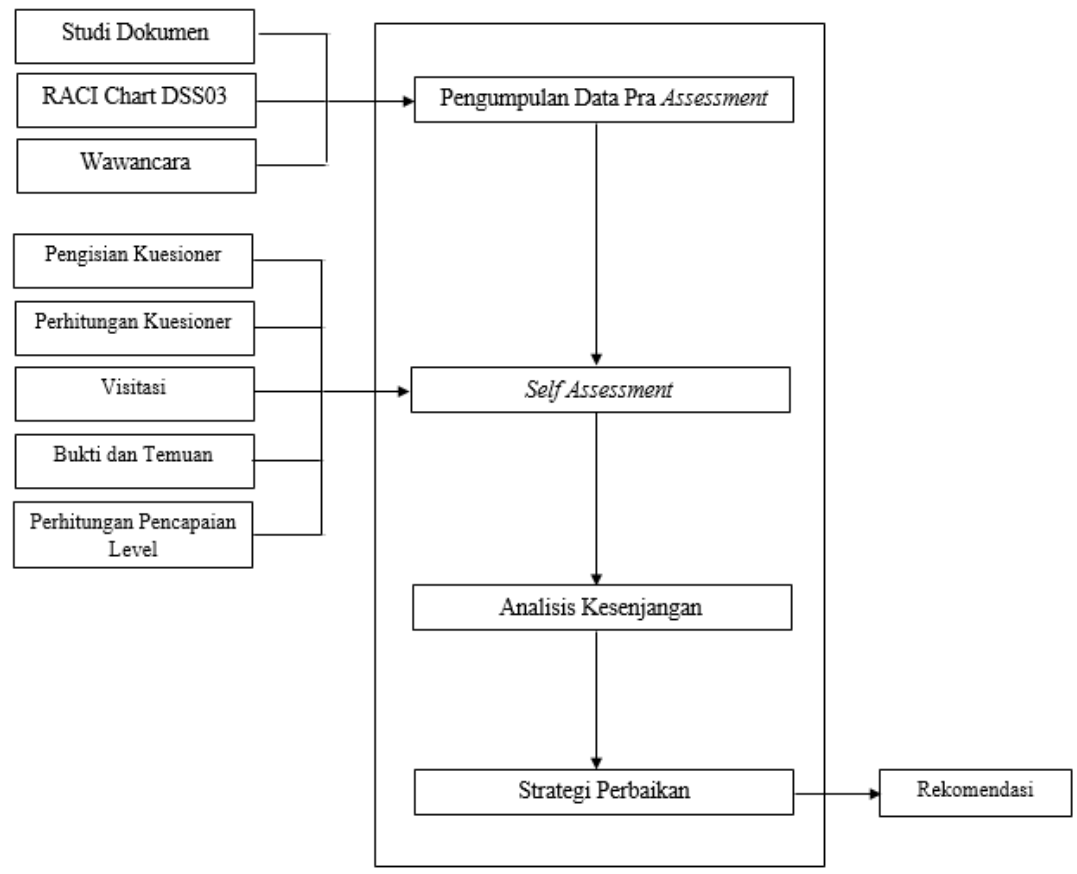

Gambar 1. Diagram Alur Tahapan Analisis Penelitian

\subsection{RACI Chart}

RACI Chart memiliki fungsi untuk mengelompokkan peran dan tanggungjawab sesuai struktur organisasi yang dimiliki suatu perusahaan. Dengan RACI Chart maka akan diketahui bahwa peran seseorang tersebut penting dalam mengelola suatu perusahaan yang berbasis teknologi informasi. Dalam penelitian ini RACI Chart digunakan untuk memetakan responden dalam pengisian kuesioner terkait dengan penelitian yang dilakukan. Berikut ini merupakan pemetaan responden yang disesuaikan dengan RACI Chart DSS03 :

Tabel 1. Pemetaan RACI Chart DSS03

\begin{tabular}{|c|c|c|c|c|c|}
\hline $\begin{array}{c}\text { Manajemen Practices } \\
\text { Sub Domain DSS03 }\end{array}$ & 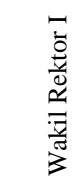 & 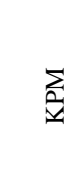 & $\begin{array}{l}\overline{2} \\
\underline{\omega} \\
\underline{5}\end{array}$ & 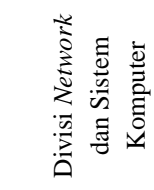 & $\stackrel{\square}{a}$ \\
\hline $\begin{array}{l}\text { DSS03.01 (Identify and } \\
\text { Classify Problems) }\end{array}$ & $\mathrm{C}, \mathrm{I}$ & I & $\mathrm{R}, \mathrm{C}$ & $\mathrm{R}, \mathrm{C}, \mathrm{I}$ & A \\
\hline $\begin{array}{l}\text { DSS03.02 (Investigate and } \\
\text { Diagnose Problems) }\end{array}$ & & & A, C & $\mathrm{R}, \mathrm{A}, \mathrm{I}$ & $\mathrm{R}$ \\
\hline $\begin{array}{l}\text { DSS03.03 (Raise Known } \\
\text { Errors) }\end{array}$ & & & A & $\mathrm{R}, \mathrm{A}$ & $\mathrm{R}$ \\
\hline $\begin{array}{l}\text { DSS03.04 (Resolve and Close } \\
\text { Problems) }\end{array}$ & $\mathrm{C}, \mathrm{I}$ & $\mathrm{C}$ & $\mathrm{R}, \mathrm{C}, \mathrm{I}$ & $\mathrm{R}, \mathrm{I}$ & A \\
\hline $\begin{array}{l}\text { DSS03.05 (Perform Proactive } \\
\text { Problems Management) }\end{array}$ & $\mathrm{C}$ & & $\mathrm{R}, \mathrm{C}$ & $\mathrm{R}$ & A \\
\hline
\end{tabular}




\subsection{Wawancara dan Studi Dokumen}

Wawancara yang dilakukan dengan menyusun daftar pertanyaan yang ditujukan kepada narasumber, yaitu kepala penanggungjawab dari bagian yang terkait dengan Sistem Informasi Akademik Universitas Dian Nuswantoro (SiAdin). Sedangkan studi dokumen dalam penelitian ini merupakan berkas - berkas dokumen tertulis maupun dokumen non fisik (yang terdapat dalam sistem) terkait dengan pengelolaan masalah pada Sistem Informasi Akademik Universitas Dian Nuswantoro (SiAdin).

\subsection{Kuesioner}

Kuisioner adalah kumpulan pertanyaan yang dibuat oleh peneliti kemudian diserbarkan secara manual agar di isi oleh responden yang sudah dipetakan sesuai dengan RACI Chart DSS03. Kuisioner digunakan untuk mengetahui tingkat kapabilitas terkait dengan pengelolaan masalah pada Sistem Informasi Akademik Universitas Dian Nuswantoro (SiAdin).

Berikut ini merupakan rumus untuk menghitung rata - rata persentase kuesioner setiap jawaban :

$$
\text { Rata }- \text { Rata Presentase }=\left[\frac{\sum(\mathrm{n} \times \text { Bobot Nilai })}{\text { Total Responden }}\right] X 100 \%
$$

Dimana $\mathrm{n}$ : total jawaban responden berdasarkan kategori jawaban kuesioner.

Bobot nilai dalam penelitian ini ditransformasikan sesuai dengan kebutuhan persentase dari Tabel 3. Dengan bobot nilai sebagai berikut :

Tabel 2. Bobot Nilai

\begin{tabular}{|c|c|c|}
\hline Abbreviation & Kategori Jawaban Kuesioner & Bobot \\
\hline N & 1 & 0 \\
\hline P & 2 & 0,325 \\
\hline L & 3 & 0,675 \\
\hline F & 4 & 1 \\
\hline
\end{tabular}

Berikut ini merupakan rumus untuk menghitung rata - rata setiap proses atribut (PA) :

$$
\text { Rata }- \text { Rata } P A=\left[\frac{\sum \text { Presentase tiap kriteria PA }}{\text { Jumlah kriteria PA }}\right]
$$

\subsection{Skala Penilaian}

Skala penilaian pada penelitian ini digunakan untuk menilai hasil dari persentase perhitungan kuesioner dan survey lapangan / visitasi untuk setiap kriteria dan proses atribut (PA). Skala penilaian ini merupakan standar ISO/IEC 15504 dan diadopsi kedalam skala penilaian COBIT 5. Skala penilaian tersebut terdiri dari :

Tabel 3. Skala Penilaian COBIT 5

\begin{tabular}{|c|l|c|}
\hline Abbreviation & \multicolumn{1}{|c|}{ Description } & \%Achieved \\
\hline N & Not achieved & 0 to 15\% achievement \\
\hline P & Partially achieved & $>15 \%$ to 50\% achievement \\
\hline L & Largely achieved & $>50 \%$ to $85 \%$ achievement \\
\hline F & Fully achieved & $>85 \%$ to $100 \%$ achievement \\
\hline
\end{tabular}




\subsection{Visitasi}

Visitasi / survey lapangan adalah penilaian yang dilakukan oleh peneliti saat melakukan penelitian dilapangan. Visitasi ini bertujuan untuk mengklarifikasi, memverifikasi dan memvalidasi pengisian kuesioner yang sudah dibagikan kepada responden terkait dengan penelitian yang dilakukan yang diperkuat dengan temuan atau bukti yang ada dilapangan.

\subsection{Analisis Tingkat Kapabilitas}

Analisis tingkat kapabilitas digunakan untuk mengetahui tingkat IT Governace yang ada pada Universitas Dian Nuswantoro. Pada tahap ini peneliti melakukan validasi terhadap kuisioner yang telah dijawab oleh responden sesuai tabel diagram RACI Chart DSS03 menggunakan visitasi yang dilakukan oleh peneliti. Rekapitulasi hasil perhitungan akan menunjukkan posisi capability level saat ini yang dapat dianalisis berdasarkan tabel rating yang dibutuhkan pada COBIT 5 yang mengacu pada COBIT 5 Self Assessment Guide [3]. Proses analisis tingkat kapabilitas dilihat berdasarkan tabel 4 berikut ini :

Tabel 4. Rating yang dibutuhkan pada COBIT 5 [3]

\begin{tabular}{cll}
\hline Level & \multicolumn{1}{c}{ Proses Atribut } & Rating \\
\hline Level 1 & Process Performance & Largely or Fully \\
Level 2 & Process Performance & Fully \\
& Performance Management & Largely or Fully \\
& Work Product Management & Largely or Fully \\
Level 3 & Process Performance & Fully \\
& Performance Management & Fully \\
& Work Product Management & Fully \\
& Process Definition & Largely or Fully \\
& Process Deployment & Largely or Fully \\
& Process Performance & Fully \\
& Performance Management & Fully \\
& Work Product Management & Fully \\
& Process Definition & Fully \\
& Process Deployment & Fully \\
& Process Measurement & Largely or Fully \\
& Process Control & Largely or Fully \\
& Process Performance & Fully \\
& Performance Management & Fully \\
& Work Product Management & Fully \\
& Process Definition & Fully \\
& Process Deployment & Fully \\
& Process Measurement & Fully \\
& Process Control & Fully \\
& Process Innovation & Largely or Fully \\
& Process Optimization & Largely or Fully \\
& & \\
& &
\end{tabular}

\subsection{Analisis Kesenjangan (Gap)}

Analisis kesenjangan (gap) berfungsi untuk mengetahui kesenjangan antara penerapan tata kelola teknologi informasi yang sudah berjalan saat ini berdasarkan posisi capability level saat ini dan tata kelola teknologi informasi yang diharapkan [4]. Analisis kesenjangan (gap) dilakukan untuk memperoleh selisih antara tingkat kapabilitas yang diterapkan saat ini dan yang diharapkan. Dari hasil analisis kesenjangan tersebut, maka dapat meningkatkan kualitas dari pengelolaan masalah pada Sistem Informasi Akademik Universitas Dian Nuswantoro (SiAdin) dengan rekomendasi strategi perbaikan yang sesuai. 


\section{HASIL DAN PEMBAHASAN}

\subsection{Hasil Studi Dokumen}

Hasil studi dokumen penelitian ini berupa dokumentasi sistem internal yang merupakan dokumen non fisik berupa website, dokumen perancangan arsitektur server dan jaringan SiAdin yang berisi rancangan arsitektur server dan jaringan SiAdin, respository git yang merupakan dokumen non fisik yang berisi rangkuman catatan kesalahan pada bahasa pemograman sistem, dan log eror server SiAdin yang merupakan catatan yang berisis log eror pada server SiAdin.

\subsection{Hasil Wawancara}

Wawancara dilakukan langsung dari narasumber yang merupakan responden dari Universitas Dian Nuswantoro, yaitu Kepala UPT PDI dan Kepala Divisi Network dan Sistem Komputer.

\subsection{Hasil Kuesioner dan Visitasi}

Berdasarkan hasil dari persentase perhitungan kuesioner dan visitasi, berikut ini merupakan pembahasan pencapaian dari setiap level beserta proses atribut (PA) :

1. Level 1 (Performed Process)

Kriteria pada level ini mengenai implementasi base practices (praktek - praktek dasar I aktivitas proses dasar) proses pengelolaan masalah pada Sistem Informasi Akademik Universitas Dian Nuswantoro (SiAdin). Pada level ini terdapat satu proses atribut yaitu Process Performance yang mencakup seberapa jauh tujuan proses pengelolaan masalah pada Sistem Informasi Akademik Universitas Dian Nuswantoro (SiAdin) telah berhasil dicapai. Pada proses ini memperoleh hasil penilaian sebesar 64,12\% dengan status Largely Achieved. Hal ini menunjukan bahwa proses pengelolaan masalah pada Sistem Informasi Akademik Universitas Dian Nuswantoro (SiAdin) yang telah diimplementasikan hanya sebagian besar tercapai tujuan prosesnya dan hasil proses belum sepenuhnya tercapai.

2. Level 2 (Managed Process)

Kriteria pada level ini mengenai kinerja dari proses pengelolaan masalah pada Sistem Informasi Akademik Universitas Dian Nuswantoro (SiAdin) diimplementasikan dengan cara dikelola yang mencakup perencanaan, pemantauan, dan penyesuaian proses. Dalam level ini terdapat dua proses atribut yaitu Performance Management dan Work Product Management. Berikut adalah hasil dari pembahasan pencapaian masing - masing atribut :

a. PA 2.1 Performance Management

Mengenai sampai dimanakah performa proses pengelolaan masalah telah dikelola dengan hasil pencapaian yang diperoleh adalah 61,67\% dengan status Largely Achieved dan menunjukan bahwa performa proses pengelolaan masalah pada Sistem Informasi Akademik Universitas Dian Nuswantoro (SiAdin) belum sepenuhnya mencapai performa proses pengelolaannya.

b. PA 2.2 Work Product Management

Mengenai sejauh mana hasil kerja yang dihasilkan oleh proses pengelolaan masalah pada Sistem Informasi Akademik Universitas Dian Nuswantoro (SiAdin) sudah dikelola dengan hasil pencapaian yang diperoleh yaitu sebesar 57,50\% dengan status Largely Achieved. Hal ini menunjukan bahwa hasil kerja dari proses pengelolaan masalah pada Sistem Informasi Akademik Universitas Dian Nuswantoro (SiAdin) belum sepenuhnya mencapai hasil kerjanya.

3. Level 3 (Established Process) 
Kriteria pada level ini mengenai proses pengelolaan masalah pada Sistem Informasi Akademik Universitas Dian Nuswantoro (SiAdin) sudah dikelola dan diimplementasikan berdasarkan standar prosedur proses (SOP) yang sudah ditentukan dan mampu untuk mencapai hasil proses yang diharapkan. Di dalam proses ini terdapat dua proses atribut yaitu Process Definition dan Process Deployment. Berikut ini adalah hasil dari pembahasan pencapaian masing - masing atribut :

a. PA 3.1 Process Definition

Mengenai sampai dimanakah Standar Operasional Prosedur (SOP) proses pengelolaan masalah pada Sistem Informasi Akademik Universitas Dian Nuswantoro (SiAdin) telah didefinisikan dengan hasil yang diperoleh adalah sebesar 0\% dengan status Not Achieved. Hal ini menunjukan bahwa pendefinisian SOP proses pengelolaan masalah pada Sistem Informasi Akademik Universitas Dian Nuswantoro (SiAdin) belum didefinisikan. Pendefinisian urutan kegiatan, identifikasi peran, identifikasi infrastruktur seperti alat atau tools, fasilitas, dan metode kegiatan proses pengelolaan masalah pada Sistem Informasi Akademik Universitas Dian Nuswantoro (SiAdin) saat ini hanya berdasarkan dokumen instruksi kerja dan hanya sebagian kecil yang tercapai pendefinsiannya.

b. PA 3.2 Process Deployment

Mengenai sampai sejauh mana Standar Operasional Prosedur (SOP) proses pengelolaan masalah pada Sistem Informasi Akademik Universitas Dian Nuswantoro (SiAdin) secara efektif digunakan / diimplementasikan dengan hasil yang diperoleh adalah sebesar 8,33\% dengan status Not Achieved. Hal ini menunjukan bahwa penyebaran dan pengimplementasian Standar Operasional Prosedur (SOP) terkait proses pengelolaan masalah pada Sistem Informasi Akademik Universitas Dian Nuswantoro (SiAdin) belum tercapai. Standar proses pengelolaan masalah saat ini hanya berdasarkan dokumen instruksi kerja dan hanya sebagian kecil yang tercapai penyebarannya kepada pegawai.

4. Level 4 (Predictable Process)

Kriteria pada level ini mengenai proses pengelolaan masalah pada Sistem Informasi Akademik Universitas Dian Nuswantoro (SiAdin) yang telah berjalan dan dioperasikan sesuai dengan batasan yang ditentukan untuk mencapai hasil proses / outcome yang diharapkan. Di dalam proses ini terdapat dua proses atribut yaitu Process Measurement dan Process Control. Berikut adalah hasil pembahasan pencapaian masing - masing atribut :

a. PA 4.1 Process Measurement

Mengenai sampai dimana hasil pengukuran digunakan untuk memastikan bahwa performa proses pengelolaan masalah pada Sistem Informasi Akademik Universitas Dian Nuswantoro (SiAdin) mendukung pencapaian sasaran kinerja proses untuk mendukung tujuan bisnis organisasi yang ditetapkan dengan hasil pencapaian yang diperoleh adalah sebesar 0\% dengan status Not Achieved. Hal ini menunjukan bahwa pengukuran performa proses pengelolaan masalah pada Sistem Informasi Akademik Universitas Dian Nuswantoro (SiAdin) belum diimplementasikan. Dimana tindakan pengukuran performa proses pengelolaan masalah pada Sistem Informasi Akademik Universitas Dian Nuswantoro (SiAdin) belum dilakukan.

b. PA 4.2 Process Control

Mengenai sejauh mana proses pengelolaan masalah pada Sistem Informasi Akademik Universitas Dian Nuswantoro (SiAdin) sudah dikelola untuk menghasilkan proses yang stabil, mampu dan bisa diprediksi dalam batasan yang telah ditentukan dengan hasil 
pencapaian yang diperoleh adalah sebesar 0\% dengan status Not Achieved. Hal ini menunjukan bahwa kontrol performa proses pengelolaan masalah pada Sistem Informasi Akademik Universitas Dian Nuswantoro (SiAdin) belum tercapai. Dimana tindakan dan pendefinisian analisa kontrol performa dan tindak lanjut hasil pengontrolan performa kegiatan proses pengelolaan masalah pada Sistem Informasi Akademik Universitas Dian Nuswantoro (SiAdin) belum tercapai dan belum ada.

5. Level 5 (Optimizing Process)

Kriteria pada level ini mengenai proses pengelolaan masalah pada Sistem Informasi Akademik Universitas Dian Nuswantoro (SiAdin) yang terprediksi secara terus menerus kemudian ditingkatkan untuk memenuhi tujuan bisnis perguruan tinggi baik saat ini dan dimasa depan. Di dalam proses ini terdapat dua proses atribut yaitu Process Innovation dan Process Optimization. Berikut adalah hasil dari pembahasan pencapaian masing - masing atribut :

a. PA 5.1 Process Innovation

Mengenai sampai dimana perubahan terkait proses pengelolaan masalah pada Sistem Informasi Akademik Universitas Dian Nuswantoro (SiAdin) diidentifikasi berdasarkan analisis penyebab umum dari adanya variasi di dalam performa dan investigasi pendekatan inovatif untuk mendefinisikan dan melaksanakan proses pengelolaan masalah dengan hasil pencapaian yang diperoleh adalah sebesar $12,00 \%$ dengan status Not Achieved. Hal ini menunjukan bahwa kontrol performa belum tercapai. Dimana tindakan dan pendefinisian rencana peningkatan dan analisa performa proses pengelolaan masalah pada Sistem Informasi Akademik Universitas Dian Nuswantoro (SiAdin) belum dilakukan.

b. PA 5.2 Process Optimization

Mengenai sejauh mana perubahan dari definisi, manajemen, dan performa proses pengelolaan masalah pada Sistem Informasi Akademik Universitas Dian Nuswantoro (SiAdin) menghasilkan dampak yang efektif untuk mencapai tujuan dari proses peningkatan dengan hasil pencapaian yang diperoleh adalah sebesar $0 \%$ dengan status Not Achieved. Hal ini menunjukan penilaian dampak dari perubahan proses pengelolaan masalah pada Sistem Informasi Akademik Universitas Dian Nuswantoro (SiAdin) belum dilakukan.

\subsection{Hasil Pencapaian Level}

Berdasarkan pembahasan diatas, berikut ini merupakan ringkasan mengenai hasil pencapaian level dengan rincian mengenai proses setiap atribut yang dicapai saat ini terkait dengan proses pengelolaan masalah pada Sistem Informasi Akademik Universitas Dian Nuswantoro (SiAdin) beserta dengan target pencapaian level yang diharapkan oleh Wakil Rektor 1 Universitas Dian Nuswantoro.

Dari apa yang terlihat pada tabel 5, maka tingkat kapabilitas tata kelola teknologi informasi terkait dengan pengelolaan masalah pada Sistem Informasi Akademik Universitas Dian Nuswantoro (SiAdin) saat ini berada pada level 1 yaitu Performed Process PA 1.1 (Process Performance) sebesar 64,12\% dengan status Largely Achieved. Status tersebut menjelaskan bahwa proses pengelolaan masalah pada Sistem Informasi Akademik Universitas Dian Nuswantoro (SiAdin) telah diimplementasikan sudah sebagian besar tercapai tujuan prosesnya, dimana hasil proses pengelolaan masalahnya belum sepenuhnya tercapai. 
Tabel 5. Ringkasan Pencapaian Level

\begin{tabular}{|c|c|c|c|c|c|c|c|c|c|}
\hline $\begin{array}{l}\text { Process } \\
\text { Name }\end{array}$ & \multicolumn{9}{|c|}{$\begin{array}{c}\text { DSS03 } \\
\text { Manage Problems }\end{array}$} \\
\hline Description & \multicolumn{9}{|c|}{$\begin{array}{l}\text { Fokus dalam upaya mengelola masalah pada SiAdin untuk mengurangi jumlah } \\
\text { masalah operasional SiAdin yang dapat diterima oleh institusi sesuai dengan tujuan } \\
\text { bisnis. }\end{array}$} \\
\hline Purpose & \multicolumn{9}{|c|}{$\begin{array}{l}\text { Meminimalisir dampak bisnis dari kurangnya pengelolaan masalah yang dapat } \\
\text { mengakibatkan terjadinya permasalah berulang yang dapat mengganggu jalannya } \\
\text { proses bisnis institusi. }\end{array}$} \\
\hline Level & Level 1 & \multicolumn{2}{|c|}{ Level 2} & \multicolumn{2}{|c|}{ Level 3} & \multicolumn{2}{|c|}{ Level 4} & \multicolumn{2}{|c|}{ Level 5} \\
\hline $\begin{array}{l}\text { Process } \\
\text { Atribut }\end{array}$ & PA 1.1 & $\begin{array}{l}\text { PA } \\
2.1\end{array}$ & $\begin{array}{l}\text { PA } \\
2.2\end{array}$ & $\begin{array}{l}\text { PA } \\
3.1\end{array}$ & $\begin{array}{l}\text { PA } \\
3.2\end{array}$ & $\begin{array}{l}\text { PA } \\
4.1\end{array}$ & $\begin{array}{l}\text { PA } \\
4.2\end{array}$ & $\begin{array}{l}\text { PA } \\
5.1\end{array}$ & $\begin{array}{l}\text { PA } \\
5.2\end{array}$ \\
\hline $\begin{array}{c}\text { Rating by } \\
\text { Precentage }\end{array}$ & $64,12 \%$ & $61,67 \%$ & $57,50 \%$ & $0 \%$ & $8,33 \%$ & $0 \%$ & $0 \%$ & $12,00 \%$ & $0 \%$ \\
\hline $\begin{array}{c}\text { Rating by } \\
\text { Criteria }\end{array}$ & $\mathrm{L}$ & $\mathrm{L}$ & $\mathrm{L}$ & $\mathrm{N}$ & $\mathrm{N}$ & $\mathrm{N}$ & $\mathrm{N}$ & $\mathrm{N}$ & $\mathrm{N}$ \\
\hline $\begin{array}{l}\text { Capability } \\
\text { Level } \\
\text { Achived }\end{array}$ & 1 & & & & & & & Tar & \\
\hline
\end{tabular}

\subsection{Analisis Kesenjangan (Gap)}

Berdasarkan tabel 5 diatas dapat ditemukan gap (kesenjangan) sebesar 4 antara nilai yang dicapai saat ini (as is) dengan target yang akan dicapai (to be). Berikut ini merupakan grafik analisis kesenjangan setiap proses atribut (PA) mulai dari level $1-5$ :

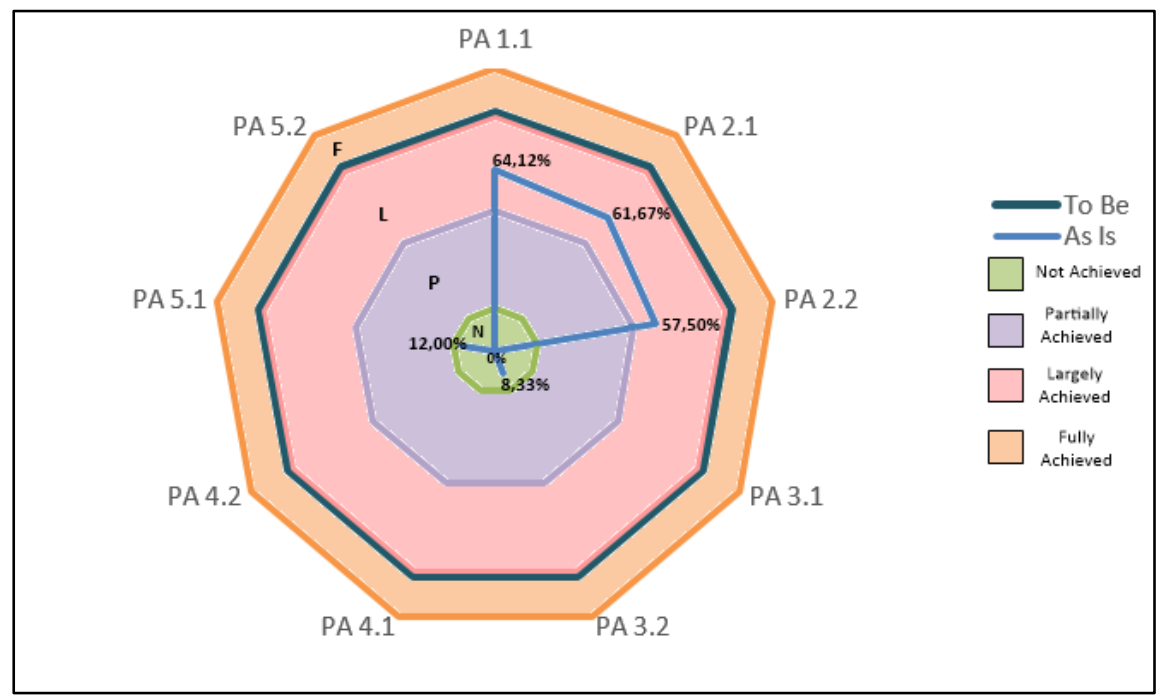

Gambar 2. Grafik Analisis Kesenjangan Proses Atribut Level 1-5

Gambar 2 diatas menunjukkan bahwa tingkat kapabilitas terkait proses pengelolaan masalah pada Sistem Informasi Akademik Universitas Dian Nuswantoro (SiAdin) saat ini yang sudah mencapai standar rating COBIT 5 mengacu pada tabel 4 hanya pada level 1 (Performed Process) PA 1.1 Process Performance dengan status Largely Achieved sebesar 64,12\%. Pada level 2 (Managed Process) PA 2.1, PA 2.2, level 3 (Established Process) PA 3.1, PA 3.2 Process Deployment, level 4 (Predictable Process) PA 4.1, PA 4.2 dan level 5 (Optimizing Process) PA 5.1, dan PA 5.2 belum mencapai standar rating COBIT 5 karena pada level 1, 2, 3, dan 4 belum berstatus Fully Achieved. 


\subsection{Strategi Perbaikan}

Strategi perbaikan pada indikator proses atribut, dimana analisa dilakukan secara bertahap dengan setiap proses atribut level 1 sampai dengan level 5 [5]. Berikut ini uraian strategi perbaikan dari setiap proses atribut:

1. PA 1.1 (Process Performance)

Strategi perbaikan untuk proses atribut PA 1.1 yaitu :

a. Melakukan pengadaan dan pemanfaatan perangkat yang diperlukan untuk membantu proses pengelolaan masalah pada sistem dan server.

b. Memberikan pelatihan kepada developer untuk membuat sistem dalam SiAdin berupa sistem pelaporan aduan user disertai dengan link yang tertera yang menunjukan bagian masalah SiAdin yang ditemui, dengan adanya sistem ini diharapkan dapat membantu proses mengidentifikasi masalah pada sistem SiAdin dan mengurai cara pengaduan manual seperti mendatangi PDI saat user menemui masalah pada SiAdin.

c. Membuat target response dan resolution time terkait kegiatan identifikasi masalah, analisis akar masalah dan jadwal penyelesaian masalah pada SiAdin. Penjadwalan waktu ini bertujuan agar kegiatan pengidentifikasian, analisis akar masalah dan penyelesaian masalah pada SiAdin dapat selesai tepat waktu dan meminimalisir dampak proses bisnis yang mungkin terjadi.

d. Menyusun dokumen catatan kesalahan berdasarkan hasil identifikasi masalah dan klasifikasi masalah, dokumen catatan kesalahan dikategorikan dalam kelompok seperti faktor teknis dan faktor non teknis, mencatat akar penyebab masalah, dan melaporkan secara berkala semua masalah yang terjadi

2. PA 2.1 (Performance Management)

Strategi perbaikan untuk proses atribut PA 2.1 yaitu :

a. Menyusun rencana proses yang didalamnya memuat tentang tujuan untuk kinerja proses pengelolaan masalah pada SiAdin, rincian rencana komunikasi proses pengelolaan masalah pada SiAdin, dan rincian rencana infrastruktur / sumberdaya proses pengelolaan masalah pada SiAdin.

b. Membuat catatan kinerja proses pengelolaan masalah pada SiAdin yang didalamnya berisi rincian hasil proses pengelolaan masalah pada SiAdin, rincian tindakan yang diambil ketika kinerja proses pengelolaan masalah tidak tercapai. Menyusun dokumen proses yang didalamnya berisi rincian tentang pemilik proses, siapa yang bertanggung jawab, dapat dipertanggungjawabkan, dikonsultasikan dan atau diinformasikan (RACI).

c. Mengkomunikasikan dengan jelas mengenai tanggung jawab para pegawai kepada pemangku kepentingan (stakeholder) Universitas Dian Nuswantoro dalam peran pengelolaan masalah pada SiAdin.

3. PA 2.2 (Work Product Management)

Strategi perbaikan untuk proses atribut PA 2.2 yaitu :

a. Menyusun rencana kualitas yang didalamnya berisi rincian kriteria kualitas proses pengelolaan masalah pada SiAdin, yang nantinya dapat digunakan sebagai indikator dalam menyelesaikan masalah, membuat dokumentasi hasil kerja dan kualitas proses pengelolaan masalah pada SiAdin.

b. Melakukan tindakan analisa lebih lanjut terhadap hasil kerja terkait proses pengelolaan masalah pada SiAdin, kegiatan ini bertujuan untuk meminimalisir risiko terulangnya kembali masalah yang sama dikemudian hari.

4. PA 3.1 (Process Definition)

Strategi perbaikan untuk proses atribut PA 3.1 yaitu :

a. Menyusun standar dan prosedur atau Standard Operational Prosedure (SOP) terkait proses pengelolaan masalah pada SiAdin.

b. Membuat metode yang digunakan untuk menilai kesesuaian kegiatan proses pengelolaan masalah pada SiAdin dengan SOP yang akan dibuat nanti. Untuk mengetahui apakah 
kegiatan tersebut sudah sesuai dengan Standard Operational Prosedure (SOP) atau belum.

5. PA 3.2 (Process Deployment)

Strategi perbaikan untuk proses atribut PA 3.2 yaitu :

a. Melakukan penilaian kinerja terkait kegiatan pengelolaan masalah pada SiAdin sesuai dengan SOP pada saat terjadi masalah pada SiAdin agar penilaian kinerja dapat berjalan sesuai dengan tujuan.

b. Memperkerjakan pegawai sesuai dengan keahlian dan pengalaman dalam kegiatan pengelolaan masalah pada sistem dan server. Memberikan pelatihan bagaimana mengelola masalah pada sistem dan server SiAdin kepada pegawai bedasarkan pada job description masing - masing.

c. Melakukan analisis dari kumpulan data hasil proses pengelolaan masalah pada SiAdin sebagai dasar perbaikan yang berkelanjutan, dengan tujuan agar permasalah yang sama tidak terulang lagi.

6. PA 4.1 (Process Measurement)

Strategi perbaikan untuk proses atribut PA 4.1 yaitu :

a. Menyusun standar penetapan pengukuran performa untuk kegiatan proses pengelolaan masalah pada SiAdin.

b. Menyusun rencana peningkatan proses dan rencana pengukuran proses pengelolaan masalah pada SiAdin

c. Membuat catatan kinerja proses, melakukan pengukuran performa kegiatan proses pengelolaan masalah SiAdin dan menganalisa hasil pengukuran performa tersebut yang bertujuan untuk memantau sampai dimana tujuan terkait proses pengelolaan masalah sudah berhasil dicapai.

7. PA 4.2 (Process Control)

Strategi perbaikan untuk proses atribut PA 4.2 yaitu :

a. Menyusun rencana pengendalian proses pengelolaan masalah SiAdin.

b. Melakukan teknik analisa dan kontrol berdasarkan rencana pengendalian proses pengelolaan masalah pada SiAdin dalam kegiatan proses pengelolaan masalah pada SiAdin yang bertujuan untuk mengukur efektifitas dari kegiatan tersebut.

c. Membuat catatan kinerja proses yang didalamnya memuat analisis dari rincian pengukuran proses pengelolaan masalah pada SiAdin serta tindakan korektif yang dilakukan.

8. PA 5.1 (Process Innovation)

Strategi perbaikan untuk proses atribut PA 5.1 yaitu :

a. Menyusun rencana peningkatan proses dan rencana perbaikan proses pengelolaan masalah SiAdin.

b. Membuat catatan kinerja proses yang didalamnya memuat analisis dari rincian pengukuran proses pengelolaan masalah pada SiAdin yang bertujuan untuk mengidentifikasi variasi masalah didalam performa proses pengelolaan masalah pada SiAdin.

c. Melakukan analisa dari data performa terkait kegiatan proses pengelolaan masalah pada SiAdin yang bertujuan untuk mengidentifikasi variasi masalah dan mengidentifikasi peluang untuk pelaksanaan praktik terbaik dalam kegiatan pengelolaan masalah pada SiAdin.

9. PA 5.2 (Process Optimization)

Strategi perbaikan untuk proses atribut PA 5.2 yaitu :

a. Menyusun rencana perbaikan proses pengelolaan masalah SiAdin.

b. Menyusun rincian strategi implementasi untuk peningkatan proses pengelolaan masalah pada SiAdin dan bukti perubahan dalam kebijakan dan standar (SOP), rencana kualitas, dan dokumentasi proses pengelolaan masalah pada SiAdin. 


\section{KESIMPULAN}

Dari hasil penelitian diatas telah dilakukan Self Assessment pengelolaan masalah pada SiAdin. Hasil penelitian diatas dapat disimpulkan :

1. Tingkat kapabilitas terkait proses pengelolaan masalah pada Sistem Informasi Akademik Universitas Dian Nuswantoro (SiAdin) saat ini yang sudah mencapai standar rating COBIT 5 mengacu pada tabel 4 hanya pada level 1 (Performed Process) PA 1.1 Process Performance dengan status Largely Achieved sebesar 64,12\% dimana proses pengelolaan masalah pada SiAdin yang telah diimplementasikan hanya sebagian besar tercapai tujuan prosesnya dan hasil proses yang ditentukan belum sepenuhnya tercapai.

2. Strategi perbaikan dapat dilakukan UPT PDI dan Divisi Network dan Sistem Komputer Universitas Dian Nuswantoro untuk mengelola masalah SiAdin.

\section{SARAN}

Untuk penelitian selanjutnya dapat melakukan perbandingan menggunakan kerangka kerja (framework) lain seperti kerangka ITIL, ISO, COSO dan lainnya.

\section{DAFTAR PUSTAKA}

[1] M. Sadikin, H. Hardi, W.H. Haji, "IT Governance Self Assessment in Higher Education Based on COBIT Case Study : University of Mercu Buana," Journal of Advanced Management Science, vol. 2, pp. 83-87, 2014.

[2] N.Y. Wijayanti, W. Setiawan, R.A. Sukamto, "Performance Assessment of IT Governance with Balanced Scorecard and COBIT 4.1 of Universitas Pendidikan Indonesia," dalam Journal of Physics : Conferences Series, Jakarta, 2017.

[3] ISACA, COBIT 5 Self Assessment Guide, USA: IT Governance Institute, 2012.

[4] ISACA, COBIT 5 Enabling Processes, USA: IT Governance Institute, 2012.

[5] ISACA, COBIT 5 A Business Framework for The Governance and Management of Enterprise IT, USA: IT Governance Institute, 2012. 